\title{
PREVALÊNCIA DOS CASOS DE COLANGIOCARCINOMA EM UM HOSPITAL UNIVERSITÁRIO
}

\section{*Maria Fernanda Chaim Correia, Ilka de Fátima Santana Ferreira Boin.}

\section{Resumo}

O colangiocarcinoma é um adenocarcinoma que acomete os ductos biliares. Apresenta prognóstico desfavorável com baixas taxas de sobrevida principalmente devido ao predomínio de diagnósticos tardios, carência de diagnósticos conclusivos e limitados recursos terapêuticos.

\section{Palavras-chave:}

Colangiocarcinoma; Fatores de risco; Sobrevida..

\section{Introdução}

O colangiocarcinoma é um adenocarcinoma que acomete os ductos biliares. ${ }^{1}$ Apresenta prevalência de $3 \%$ entre os tumores gastrointestinais e taxas de sobrevida de 5 anos inferiores a $10 \% .^{2} \mathrm{O}$ prognóstico desfavorável pode ser atribuído principalmente ao predomínio de diagnósticos tardios que por sua vez decorre de duas principais caraterísticas da doença: evolução inicial assintomática e carência de métodos diagnósticos conclusivos. ${ }^{3,4}$.

Consequentemente ao diagnóstico tardio as possibilidades terapêuticas se tornam limitadas. ${ }^{5} \mathrm{O}$ transplante hepático não é previsto pela regulações brasileiras e a ressecção na maioria dos casos não é curativa. $^{6}$

O objetivo deste trabalho consiste em aprimorar a caracterização da doença. Este estudo considera dados relativos ao perfil epidemiológico, clínico, radiológico e histopatológico dos pacientes diagnosticados com colangiocarcinoma em um hospital universitário.

\section{Resultados e Discussão}

O estudo foi aprovado pelo Comitê de Ética em Pesquisa da FCM, CAAE 51738315.9.0000.5404. Depois de analisadas cerca de 10.000 biópsias entre 1994 e 2016 foram registrados 48 diagnósticos histopatológicos de colangiocarcinoma. Destes 45 possuiam registro clínico e laboratorial completo e, portanto, inseridos no estudo. Uma vez coletados os dados, foram realizadas análises estatísticas comparando os grupos pacientes submetidos a cirurgia e tratamento clínico exclusivo; manifestação de metástase e ausência dela.

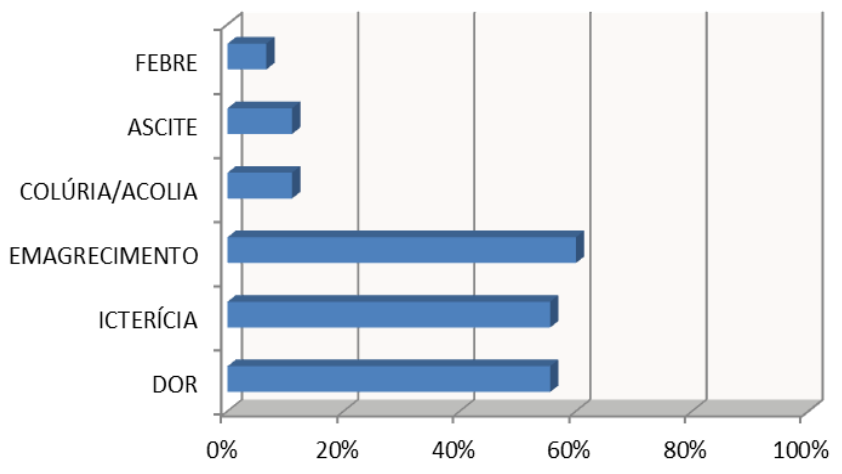

Figura 1. Frequência dos sintomas apresentados pelos pacientes na admissão.

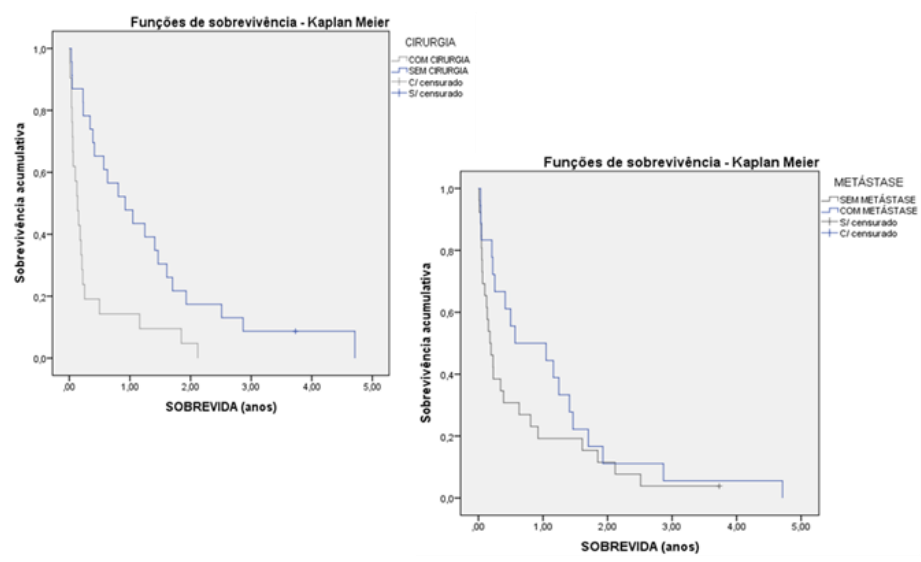

Figura 2. Sobrevida comparativa entre os pacientes submetidos a cirurgia e tratamento clínico exclusivo $p=0,001$. Sobrevida entre o grupo com metástase e sem $\mathrm{p}=0,190$.

Verificou-se também que em apenas $22,5 \%$ dos pacientes levantou-se a hipótese diagnóstica de colangiocarcinoma fazendo uso de apenas um método de imagem (ultrassom, ressonância magnética e/ou tomografia).

\section{Conclusões}

A baixa sobrevida evidenciou o predomínio de diagnósticos tardios. Pode-se concluir que ainda precisam-se aprimorar a combinação de sensibilidade e especificidade dos exames. Além disso, revelou as limitações e a baixa eficiência dos tratamentos disponíveis para os casos mais avançados.

\footnotetext{
${ }^{1}$ Vasilieva, L. E.; et al. Modern diagnostic approaches to cca Hepatobiliary Pancreat Dis Int., Grécia, v.11, n.4, 2012.

${ }^{2}$ Rizvi, S.; Gores, G. J. Pathogenesis, diagnosis, and management of cca. National Institutes of Health, EUA, v.142, n.6, p.1215-1229, 2013.

${ }^{3}$ Bridgewate, J. et al. Guidelines for the diagnosis and management of intrahepatic cca. Journal of Hepatology, EUA, v.60, n.6, p.1268-1269, 2014.

${ }^{4}$ Ghoury, Y. A.; Mian, I.; Blechacz B. Cancer review: Cholangiocarcinoma. Journal of Carcinogenes, India, v.14, 2015.

${ }^{5}$ BLECHACZ, B.; GORES, G. J. Cca: Advances in Pathogenesis, Diagnosis, and Treatment. Hepatology, EUA, v.48, n.1, p.308-321, 2008

${ }^{6}$ Gayotto, L. C. d. C.; Alves, V. A. Doenças do fígado e das vias biliares. Brasil, v.2, p.105-123. Atheneu,. 2001.
} 